\title{
Numerical Simulation Analysis of Unsteady Temperature in Thermal Insulation Supporting Roadway
}

\author{
Shuguang Zhang, ${ }^{1,2}$ Pingping Lu, ${ }^{3}$ and Hongwei Wang $\mathbb{D}^{4}$ \\ ${ }^{1}$ School of Civil and Architectural Engineering, Guilin University of Technology, Guilin 541000, China \\ ${ }^{2}$ Guangxi Key Laboratory of Geomechanics and Geotechnical Engineering, Guilin 541004, China \\ ${ }^{3}$ School of Civil Engineering, Liaoning Technical University, Fuxin 123000, China \\ ${ }^{4}$ Institute of Science and Technology, Taiyuan University of Technology, Taiyuan 030024, China
}

Correspondence should be addressed to Hongwei Wang; wanghongwei01@tyut.edu.cn

Received 28 April 2019; Accepted 23 May 2019; Published 10 June 2019

Academic Editor: Javier Martinez Torres

Copyright (c) 2019 Shuguang Zhang et al. This is an open access article distributed under the Creative Commons Attribution License, which permits unrestricted use, distribution, and reproduction in any medium, provided the original work is properly cited.

\begin{abstract}
High geothermal hazard is a basic problem that must be solved in deep mining; thereby the research on thermal insulation supporting for high temperature control of deep roadway is increasing. However, the quantitative analysis of its thermal insulation effect is yet to be carried out. By building the physical model and control equations of the thermal insulation supporting roadway and considering heat-humidity transfer at wall, the temperature field distribution of surrounding rock and airflow is numerically calculated. Based on numerical simulation results, the evolution law of temperature with ventilation time is analyzed at airflow inlet, outlet, and different sections, then the variation law of surface heat transfer coefficient with position and time is obtained. For heat insulation support structure, the results show that it is not obvious to change the distribution law of temperature field, but it is effective to weaken the convection heat transfer between surrounding rock and airflow. In the main airflow area, the rate of heat exchange gradually decreases with the heat exchange becoming more and more sufficient; in boundary layer, the airflow temperature quickly transits from the wall temperature to that of the main airflow area because of intense collisions of airflow masses, so the mechanism of temperature change is different. The surface heat transfer coefficient well reflected the unstable heathumidity transfer, especially in the beginning of ventilation or at airflow inlet. Therefore, the heat insulation supporting structure is helpful to the auxiliary cooling of high temperature mine.
\end{abstract}

\section{Introduction}

As the exploitation goes deeper and deeper, high geothermal hazards have become a prominent problem affecting mine production and management [1]. In China, the exploitation depth of many mines is more than 1,000 meters, and the temperature gradient of coal stratum is $25-30^{\circ} \mathrm{C} / \mathrm{km}$ on average. According to incomplete statistics, there are nearly 150 high geothermal coal mines in China and their temperature of workface is usually $30-40^{\circ} \mathrm{C}$ [2]. For example, in Sanhejian coal mine of Xuzhou Mining Group, China, the surrounding rock temperature of $-980 \mathrm{~m}$ mining level is up to $46.8^{\circ} \mathrm{C}$ [3]. Therefore, the prevention and control of mine high temperature have become one of the basic problems that must be solved in deep mining.

With the excavation of deep roadway, the balance state of original temperature in rock stratum is destroyed, which results the temperature field in surrounding rock to change dynamically $[4,5]$. Scholars and engineers have done a lot of research on temperature distribution in surrounding rock. Since the 1990s, the research of surrounding rock temperature field in underground engineering has been increased gradually, and the temperature field model has been established and the heat transfer characteristics of surrounding rock have been studied $[6,7]$. In recent years, finite element method and finite volume method are also used to simulate the temperature field of roadway surrounding rock $[8,9]$. With the wide application of numerical calculation methods, the distribution of temperature field [10, 11], the analysis of influencing factors $[12,13]$, and the characteristics of heat and moisture exchange [14-16] are analyzed. In the site investigation and experimental testing, similar experimental platform for temperature field of roadway surrounding rock 
was established, and the unsteady state process of temperature field of roadway surrounding rock was analyzed [4, 17]. The above research results explain the distribution law of surrounding rock temperature field in high temperature roadway and point out that the heat transfers from deep surrounding rock to air flow in the roadway are the key factors. The preliminary study shows that the heat exchange between surrounding rock and airflow can be greatly reduced by adopting the heat insulation supporting structure, but the quantitative description of its effect needs further study. In this paper, based on the unsteady heat and mass transfer mechanism of ventilation roadway and the law of energy conservation and the heat transfer law of composite medium, the unsteady heat and mass transfer mathematical model of heat insulation roadway is established to quantitatively analyze the influence of thermal insulation supporting and ventilation time on airflow temperature.

\section{Mechanism of Unsteady Heat Transfer in Ventilation Roadway}

The airflow, provided by the draught fan or cooling fan, is different from the natural convection of airflow in the roadway. When the ventilated airflow flows in the moist wall of roadway, the airflow velocity decreases due to the viscous force near the wall, and the wind resistance increases as closing the wall. Near the wall, airflow is in a state without slip; that is, no slip boundary condition is satisfied. Subjected to the viscous force, airflow velocity changes from zero to that of the main airflow in the flow boundary layer, and the thickness of boundary layer increases continuously along the flow direction. However, with the interaction of viscous force and inertial force, the flow state inside the boundary layer becomes more and more unstable, and it gradually transitions from laminar flow state to turbulent flow state. But near the wall surface, the viscous force occupies a dominant position, which is still reflected as viscous laminar flow. Since the temperature field and humidity field of airflow are affected by the flow state of airflow in the roadway, the concept of flow boundary layer can be extended to convection heat and mass transfer. Therefore, the thin layer with drastic changes in fluid temperature near the wet wall of the roadway is called the thermal boundary layer (transition layer), and the thin layer with drastic changes in humidity near the wet wall is called the wet boundary layer (viscosity layer). The boundary layer is composed of transition layer and viscous layer. Based on the above understanding, the temperature and humidity field of the convective heat and mass transfer problem in the roadway can be divided into two regions: the boundary layer and the mainstream region (as shown in Figure 1).

The heat and mass transfer process in the entire fluid region can be described as follows: because the airflow that is tight against the wall is stationary relative to the surface of wall and its velocity is zero, the heat transfer from the surrounding rock to the roadway wall and the moisture transfer through the nonslip static layer are heat transfer and mass diffusion. The amount of heat (moisture) passes through the extremely thin static layer and then enters the boundary layer with laminar flow or turbulent flow. In this boundary

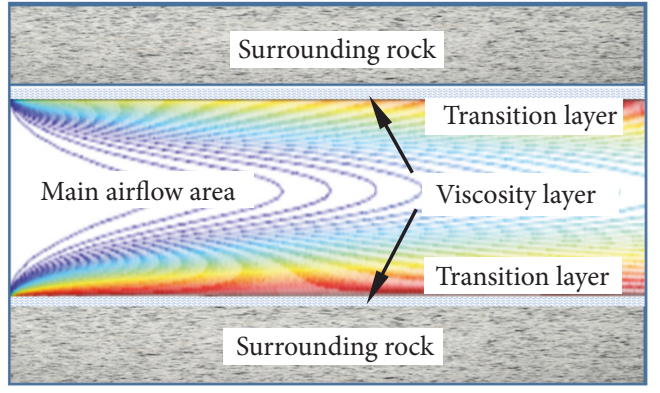

FIGURE 1: Division of airflow flow in roadway.

layer, each part of the airflow occurs relative displacement. Due to temperature and humidity difference and pressure difference, the acute motion appears when hot and cold gases meet dry and wet gases. On the one hand, the heat and humidity are transferred from the high temperature wet microsphere to that of low-temperature by the convection of the fluid microsphere. On the other hand, the heat-moisture conduction between fluid molecules occurs through the heat-moisture diffusion of airflow molecules. Convection heat transfer, mass transfer, and heat-moisture diffusion will work at the same time in these processes. In the main airflow area, the heat-humidity transfer increases the temperature and humidity of airflow mainly through the heat and humidity diffusion between molecules. In the whole airflow region, under the coupling effect of convective heat transfer and convective mass transfer, the evaporation (phase transformation) of the liquid attached to wet wall will increase the quality of airflow, which not only increases the thermal conductivity of airflow, but also accelerates the convection heat transfer between wet wall and airflow. At the same time, the increase of airflow temperature accelerates the evaporation of liquid and the moisture transfer inside airflow, also improves the saturation of airflow, and accelerates the mass transfer between wet wall and airflow.

\section{Mathematical Model of Unsteady Heat Transfer}

3.1. Basic Assumptions of the Model. The simulated roadway is an insulated concrete supporting roadway; that is, the ordinary shotcrete is replaced by insulated concrete [18]. Compared to ordinary concrete, the coarse and fine aggregate of concrete are replaced by a certain proportion of ceramsite and glass bubbles, so as to reduce its thermal conductivity. At the same time, its strength should also meet the requirements of roadway support structure. The physical model of roadway supported with thermal insulation concrete is shown in Figure 2.

The assumptions of the physical model are as follows:

(1) Surrounding rock is homogeneous and isotropic, and its thermophysical properties are stable. The insulated concrete is homogeneous and isotropic.

(2) The cross section of the roadway is round, and the heat insulation supporting and surrounding rock form an infinite hollow cylinder. 


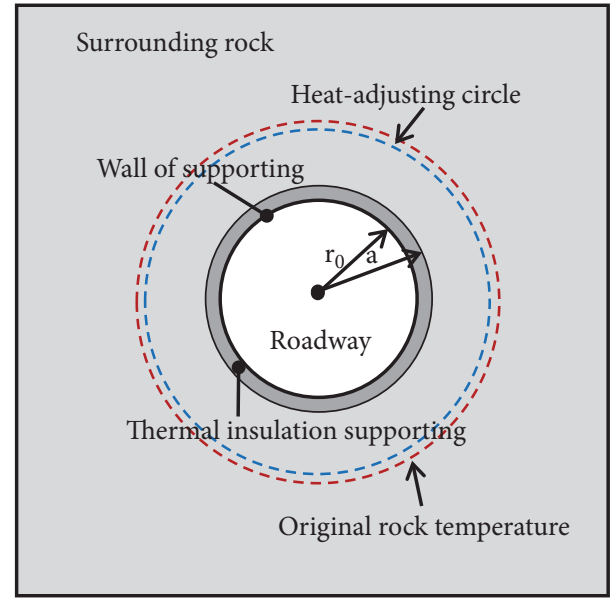

FIGURE 2: The physical model of roadway.

(3) Before excavation, the temperature of surrounding rocks in each part of the roadway is the same, which is the original rock temperature.

(4) The two-dimensional unsteady heat and moisture exchange along the radial and axial directions is studied without considering the heat-moisture exchange along circumferential direction.

(5) The thermal radiation of surrounding rock and the heat dissipation of mechanical equipment in the roadway are not considered, and the heat emission resulting from coal oxygen is ignored.

(6) Ignore moisture diffusion due to temperature and pressure gradients.

\subsection{Governing Equation}

3.2.1. Differential Equation of Unsteady Heat Conduction of Surrounding Rock. Based on the basic assumption, the heat dissipation problem of surrounding rock along the axis is simplified [8]. According to the law of conservation of energy and Fourier law, the integral equation of unsteady heat conduction in the temperature field of roadway surrounding rock is established as [13]

$$
\rho_{i} C_{i} \frac{\partial T_{i}}{\partial t}=\lambda_{i} \frac{\partial^{2} T_{i}}{\partial r^{2}}+\frac{1}{r} \frac{\partial T_{i}}{\partial r}+\frac{\partial^{2} T_{i}}{\partial z^{2}}
$$

where $\rho$ is density, $\mathrm{kg} / \mathrm{m}^{3} ; C$ is specific heat capacity, $\mathrm{J} /\left(\mathrm{kg} \cdot{ }^{\circ} \mathrm{C}\right) ; \lambda$ is heat conduction coefficient, $\mathrm{W} /\left(\mathrm{m} \cdot{ }^{\circ} \mathrm{C}\right) ; \mathrm{T}$ is temperature, ${ }^{\circ} \mathrm{C}$; the subscript $i$ means airflow, surrounding rock, and supporting, respectively.

3.2.2. Heat-Moisture Exchange at the Wall Surface. The surrounding rock transfers heat to the roadway wall surface and then transfers it to the airflow by convection and mass transfer. According to the energy balance principle, the heat balance equation is established at the wall surface.

$$
\left.\lambda_{\mathrm{s}} \frac{\partial T}{\partial r}\right|_{r=r_{0}}=\frac{h_{\mathrm{L}} \eta \Delta Q}{2 \pi r_{0}}+\alpha\left(T_{\mathrm{W}}-T_{\mathrm{f}}\right)
$$

where $r$ is the radius and $r_{0}$ is the radius of roadway, $\mathrm{m} ; h_{\mathrm{L}}$ is latent heat of water vaporization, $\mathrm{kJ} / \mathrm{kg} ; \eta$ is the percentage of water evaporation, $\% ; \Delta Q$ is total moisture evaporation in unit time and length, $\mathrm{kg} /(\mathrm{m} \cdot \mathrm{h}) ; \alpha$ is the coefficient of convection heat transfer, $\mathrm{kJ} /\left(\mathrm{m}^{2} \cdot \mathrm{h} \cdot{ }^{\circ} \mathrm{C}\right) ; T_{\mathrm{w}}$ and $T_{\mathrm{f}}$ represent temperature of wall and airflow, respectively.

The wall temperature is distributed along the axis:

$$
\frac{\partial T}{\partial z}=\frac{q_{\mathrm{f}}}{M_{B}\left(C_{\mathrm{pa}}+C_{\mathrm{pv}} d\right)}
$$

where $q_{\mathrm{f}}$ is the total heat of change in airflow temperature, $\mathrm{kJ} ; M_{B}$ is the mass flow of airflow, $\mathrm{kg} / \mathrm{h} ; C_{\mathrm{pa}}$ and $C_{\mathrm{pv}}$ are specific heat capacity of airflow and water vapor, respectively, $\mathrm{kJ} /\left(\mathrm{kg} .{ }^{\circ} \mathrm{C}\right) ; d$ is the moisture content of airflow.

3.2.3. Energy Conservation Equation. In order to obtain the mathematical model of airflow temperature field in the roadway, the energy conservation equation established is as follows:

$$
\frac{\partial T}{\partial t}+v_{\mathrm{f}} \frac{\partial T}{\partial z}=\frac{\alpha U}{\rho_{\mathrm{f}} A C_{\mathrm{p}}}\left(T_{\mathrm{W}}-T_{\mathrm{f}}\right)
$$

where $v_{\mathrm{f}}$ is the speed of airflow, $\mathrm{m} / \mathrm{s} ; \rho_{\mathrm{f}}$ is the velocity and density of airflow, $\mathrm{m}^{3} / \mathrm{kg}$; $U$ is the perimeter of the section, $\mathrm{m} ; A$ is the cross-sectional area of the roadway, $\mathrm{m}^{2}$.

3.3. Boundary Conditions and Initial Conditions. (1) Boundary conditions are as follows:

When $r=\mathrm{r}_{0}$,

$$
\lambda_{\mathrm{s}} \frac{\partial T}{\partial r}=\alpha\left(T_{\mathrm{W}}-T_{\mathrm{f}}\right)
$$

When $r=a$,

$$
\begin{gathered}
T_{\mathrm{s}}(r, z, t)=T_{\mathrm{R}}(r, z, t) \\
\lambda_{\mathrm{s}} \frac{\partial T_{\mathrm{s}}}{\partial r}=\lambda_{\mathrm{R}} \frac{\partial T_{\mathrm{r}}}{\partial r}
\end{gathered}
$$

When $r=\infty$,

$$
T_{\mathrm{r}}(\infty, z, t)=T_{\mathrm{R} 0}
$$

(2) Initial conditions are as follows:

$$
\begin{aligned}
& T_{\mathrm{s}}(r, z, 0)=T_{\mathrm{w}} \\
& T_{\mathrm{f}}(r, 0,0)=T_{\mathrm{f} 0}
\end{aligned}
$$

where $T_{i}$ is temperature, ${ }^{\circ} \mathrm{C}$; the subscripts $\mathrm{r}$, s, f mean surrounding rock, supporting, and airflow, respectively.

\section{Numerical Simulation of Unsteady Temperature Field}

The ANSYS FLUENT module was used to simulate the unsteady temperature field of the heat insulation support roadway and analyze the space-time evolution law of the ventilation airflow temperature field in 2 years, so as to observe the heat insulation effect of the heat insulation layer and provide reference for the active cooling technology of the high temperature mine. 
TABLE 1: Initial calculation parameter.

\begin{tabular}{lccccccccc}
\hline$\lambda$ & $\begin{array}{c}\lambda_{\mathrm{r}} \\
\mathrm{W} /\left(\mathrm{m} \cdot{ }^{\circ} \mathrm{C}\right)\end{array}$ & $\begin{array}{c}\lambda_{\mathrm{s}} \\
\mathrm{W} /\left(\mathrm{m} \cdot{ }^{\circ} \mathrm{C}\right)\end{array}$ & $\begin{array}{c}h_{\mathrm{L}} /\left(\mathrm{m} \cdot{ }^{\circ} \mathrm{C}\right) \\
\mathrm{k} / \mathrm{kg}\end{array}$ & $\begin{array}{c}\Delta Q \\
\mathrm{~kg} /(\mathrm{m} \cdot \mathrm{h})\end{array}$ & $\begin{array}{c}\alpha \\
\mathrm{kJ} /\left(\mathrm{m}^{2} \cdot \mathrm{h} \cdot{ }^{\circ} \mathrm{C}\right)\end{array}$ & $\begin{array}{c}\eta \\
\%\end{array}$ & $\begin{array}{c}d \\
\%\end{array}$ & $\begin{array}{c}C_{\mathrm{pa}} \\
\mathrm{kJ} /\left(\mathrm{kg} \cdot{ }^{\circ} \mathrm{C}\right)\end{array}$ & $\begin{array}{c}C_{\mathrm{pv}} \\
\mathrm{kJ} /\left(\mathrm{kg} \cdot{ }^{\circ} \mathrm{C}\right)\end{array}$ \\
\hline 0.0242 & 2.415 & 0.29 & 2420 & 0.5026 & 50.4 & 20 & 70 & 1.004 & 1.85 \\
\hline
\end{tabular}

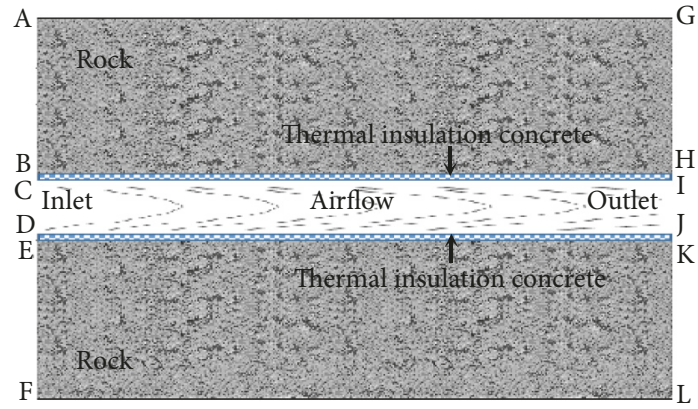

FIGURE 3: Sketch map of simplified model.

4.1. Physical Model. Considering that the radius of the thermostat is about 6 times the size of the roadway, to ensure the accuracy of calculation, the height of the model is set as $100 \mathrm{~m}$ (the radius of the roadway $r_{0}$ is $2.0 \mathrm{~m}$ ). The whole solution range is the rectangular area of $100 \mathrm{~m} \times 200 \mathrm{~m}$, as shown in Figure 3.

The calculation method and steps are as follows

Start GAMBIT and run the solver (FLUENT/UNS); at the same time, a rectangle of $\mathrm{X}=200 \mathrm{~m}$ and $\mathrm{Y}=100 \mathrm{~m}$ is created, and the AFLG area is set as the main body of surrounding rock.

(2) After setting the boundary between wall rock and support (BH and $\mathrm{EK})$ and the boundary between support and roadway airflow (CI and DJ), the SPLIT tool was used to segment AFLG region, and the surrounding rock region, support region, and airflow region were obtained, respectively.

(3) Starting from the central axis of the roadway, the mesh was divided along the radius in accordance with the principle of inner density and outer thinning. The mesh ratio was 1.02, the interval size was 1 , and the mesh type was tetrahedron.

(4) The boundary is set as follows: line CD is set as velocity-inlet of airflow, and line IJ is the outlet correspondingly. The outlet of airflow is set as the free outflow boundary because the temperature, speed, and pressure of airflow are unknown. Then, the remaining boundaries are set as solid boundary.

(5) Set the media type of different computing areas, save the modeling file, and output the grid file.

4.2. Initial Condition. The thickness of Insulating concrete is $200 \mathrm{~mm}$, and the original rock temperature $T_{R 0}$ is $36.5^{\circ} \mathrm{C}$. For AG and FL interfaces, since they are far away from the range of the heat-adjusting circle, its temperature is not affected by airflow and set as the original rock temperature $T_{R 0}$. The atmospheric pressure is $108.9 \mathrm{kPa}$. Airflow temperature at inlet is $20^{\circ} \mathrm{C}$ and its velocity is $1.5 \mathrm{~m} / \mathrm{s}$, then the mass flow of airflow $M_{B}$ can be calculated. The density and dynamic viscosity of airflow are $1.2225 \mathrm{~kg} / \mathrm{m}^{3}$ and $1.7894 \times 10^{-5} \mathrm{~kg} / \mathrm{m} \cdot \mathrm{s}$, respectively. Other calculation parameters are listed in Table 1.

4.3. Numerical Results of Unsteady Temperature Field. FLUENT software was used to simulate the changes of the temperature field in the roadway at $6,12,18$, and 24 months for ventilation, respectively. The temperature field distribution of the roadway at different ventilation times is shown in Figure 4.

For the roadway surrounding rock, the radius of heatadjusting circle gradually expands with the increase of ventilation time and finally tends to be stable. This is consistent with the actual engineering situation and the research results of other scholars. To further analyze the temperature distribution of airflow, 10 sections were intercepted at $20 \mathrm{~m}$, $40 \mathrm{~m}, 60 \mathrm{~m}, 80 \mathrm{~m}, 100 \mathrm{~m}, 120 \mathrm{~m}, 140 \mathrm{~m}, 160 \mathrm{~m}, 180 \mathrm{~m}$, and $200 \mathrm{~m}$ in the axial direction. The airflow temperature at different radial positions under the action of ventilation was extracted. Using Origin software, the change curve of airflow temperature at each section was drawn in Figure 5, and the change curve of average temperature at outlet was drawn in Figure 6.

The numerical results show that the variation trend of the airflow temperature is similar in radial direction under the action of ventilation time. The overall trend is nonlinear increase, but the increasing amplitude decreases with time. In axial direction, when the ventilation time is the same, the variation trend of airflow temperature is similar also at each section. But the value of temperature increases gradually; the distance between the temperature curves of different sections decreases correspondingly.

At the inlet and outlet, the temperature difference of airflow in radial and axial direction gradually decreases with the increases of ventilation time. At the sections $x=20 \mathrm{~m}$, $\mathrm{x}=40 \mathrm{~m}$ and $\mathrm{x}=60 \mathrm{~m}$, because the heat transfer is extremely inadequate, the local temperature is equal to the initial temperature of airflow. In the middle and rear areas of the roadway along airflow direction, as the heat exchange becomes more and more sufficient, the rate of heat exchange gradually decreases. Accordingly, the heat dissipation from surrounding rock to airflow decreases. In boundary layer, intense collisions of airflow masses result in the increase of convective heat transfer rate and temperature gradient. Therefore, the temperature of airflow quickly approaches that of the wall temperature.

The airflow temperature at outlet is a direct reflection of heat transfer effect. The simulation results show that the airflow reaches the outlet around 150s. Thereafter the temperature of airflow at outlet begins to decrease rapidly, and it has been changed from $33^{\circ} \mathrm{C}$ to $29.5^{\circ} \mathrm{C}$ when ventilation lasts 300s. During this time, the convection heat transfer directly occurred between the ventilation airflow and the original 


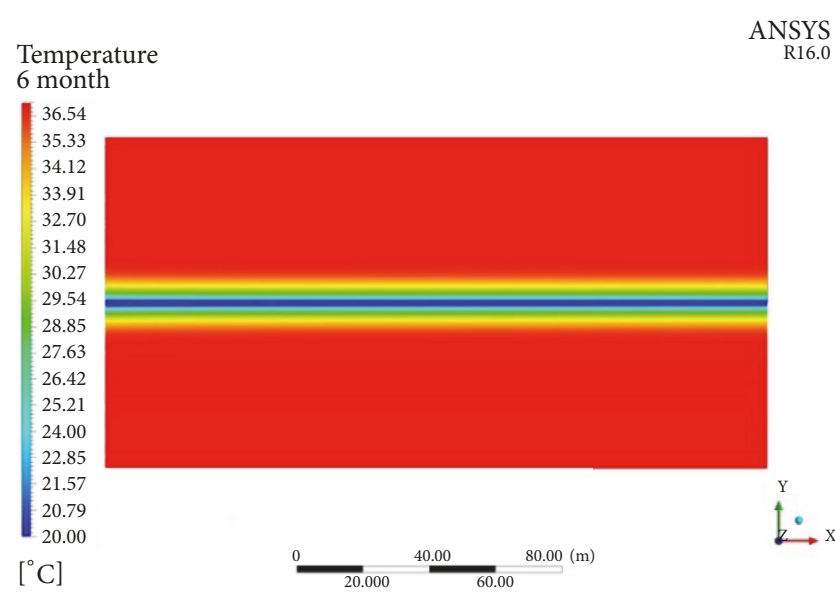

(a) Ventilation for 6 months

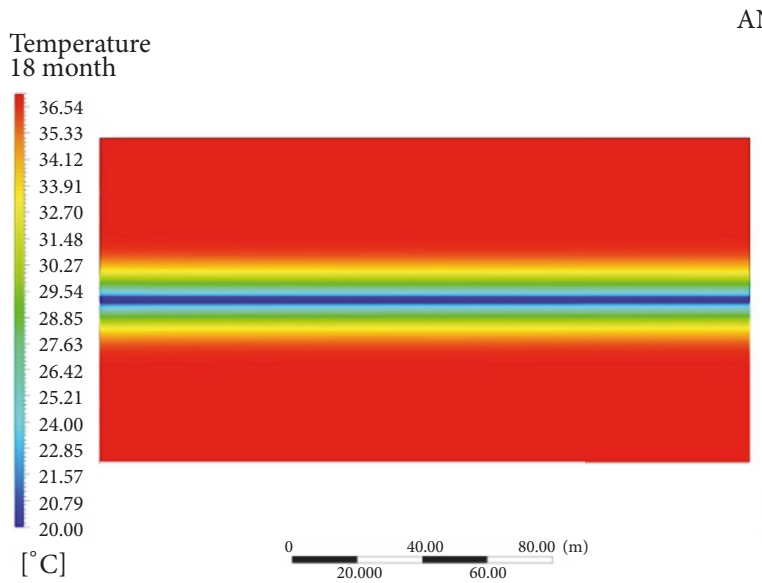

(c) Ventilation for 18 months

$\stackrel{t \rightarrow x}{\longrightarrow}$

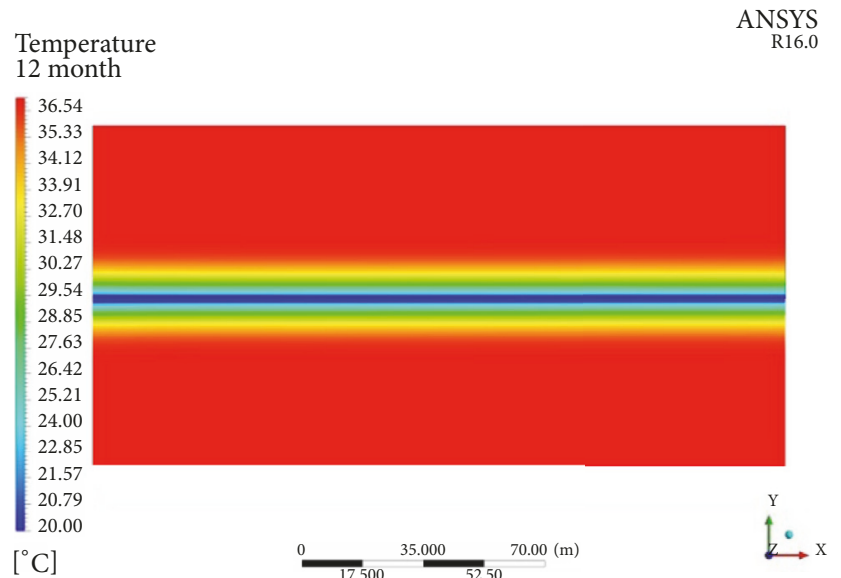

(b) Ventilation for 12 months

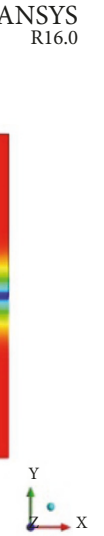

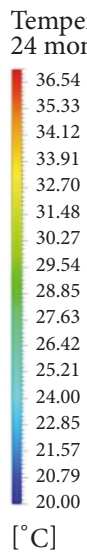

Figure 4: Temperature field of roadway at different time.

airflow in the roadway, which was the fastest stage in process of temperature change. After 300s, the rate of temperature decline at outlet begins to slow down, and the average temperature decreases with the increase of ventilation time accordingly. After 400s, the heat-moisture exchange between surrounding rock and airflow current plays a leading role. The airflow temperature at outlet changes frequently and becomes stable after 12 hours. Under the action of heat insulation support, the temperature of airflow decreases gently, which indicates that the heat transfer rate from surrounding rocks to the roadway gradually decreases. For 2 years, the temperature of airflow at outlet is stable at about $23.5^{\circ} \mathrm{C}$, just taller about $3.5^{\circ} \mathrm{C}$ than the initial temperature of airflow at inlet. The calculation results show that the heat exchange between surrounding rock and airflow in roadway is hindered by the thermal insulation supporting, and the thermal environment in the roadway can be effectively improved.

4.4. Analysis of Surface Heat Transfer Coefficient. The surface heat transfer coefficient $\left(K_{\tau}\right)$ is a variable affected by many factors. Based on A.Н.Шербань's research results of mine cooling theory, without considering the local heat source, the heat balance equation of roadway is [19]

$$
\begin{gathered}
M_{B}\left[C_{\mathrm{pa}}\left(T_{2}-T_{1}\right)+h_{L}\left(x_{2}-x_{1}\right)\right. \\
=K_{\tau} U L\left[T_{R 0}-\frac{1}{2}\left(T_{1}+T_{2}\right)\right]
\end{gathered}
$$

where $K_{\tau}$ is surface heat transfer coefficient, $\mathrm{kW} /\left(\mathrm{m}^{2} \cdot{ }^{\circ} \mathrm{C}\right) ; T_{1}$ and $T_{2}$ are airflow temperature at beginning and end, respectively, ${ }^{\circ} \mathrm{C}$; the other symbols have the same meaning as before.

To explore the change rule of $K_{\tau}$ with the time and location, five sections, located at $\mathrm{x}=5 \mathrm{~m}, 50 \mathrm{~m}, 80 \mathrm{~m}, 130 \mathrm{~m}$, and $180 \mathrm{~m}$, are selected along the axis direction. The changes of $K_{\tau}$ at different moments with the axial locations were drawn in Figure 7, and the changes of $K_{\tau}$ at different locations with the ventilation time were drawn in Figure 8.

$K_{\tau}$ increases gradually along the axial depth, and its growth rate is obvious in the range of $25 \mathrm{~m}$ near the inlet. It is the most obvious stage of heat exchange near inlet, because the temperature difference between surrounding rock and airflow is larger. When the axial depth exceeds $25 \mathrm{~m}$, the growth rate of $K_{\tau}$ tends to moderate but presents certain 


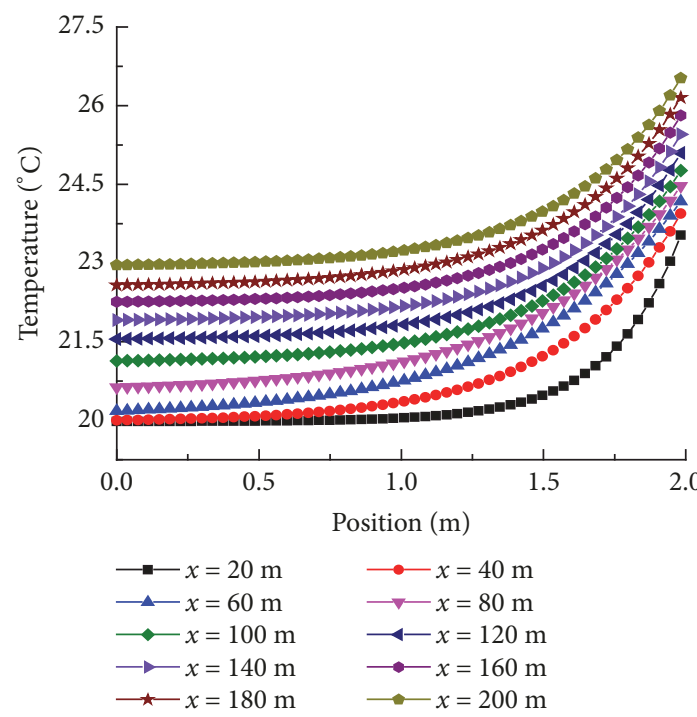

(a) Ventilation for 6 months

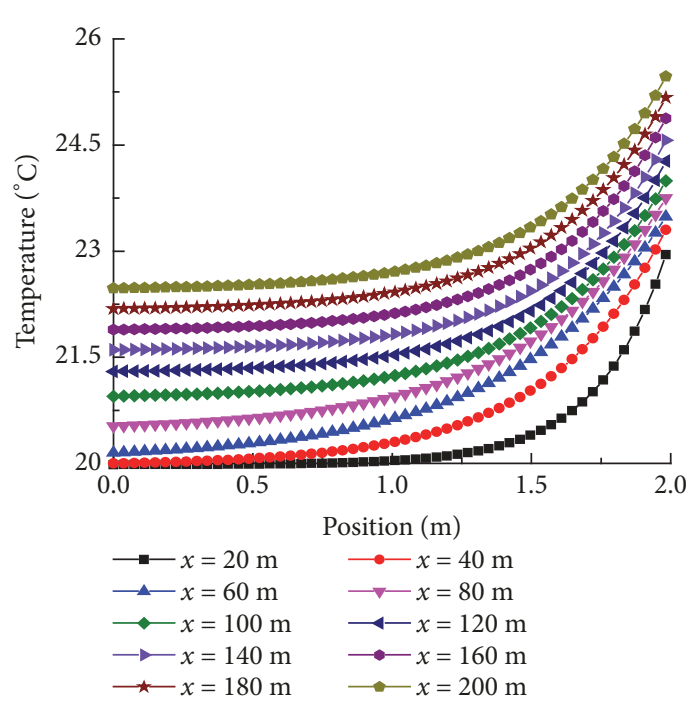

(c) Ventilation for 18 months

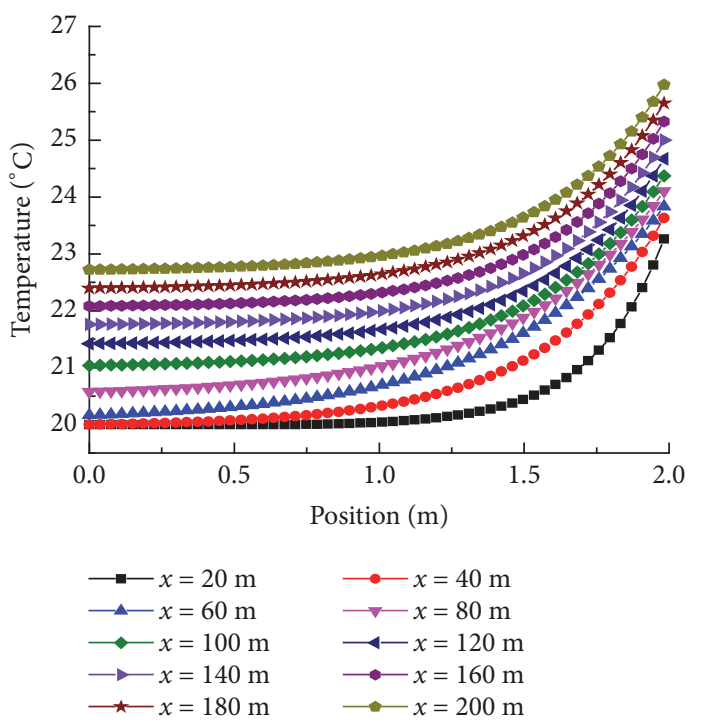

(b) Ventilation for 12 months

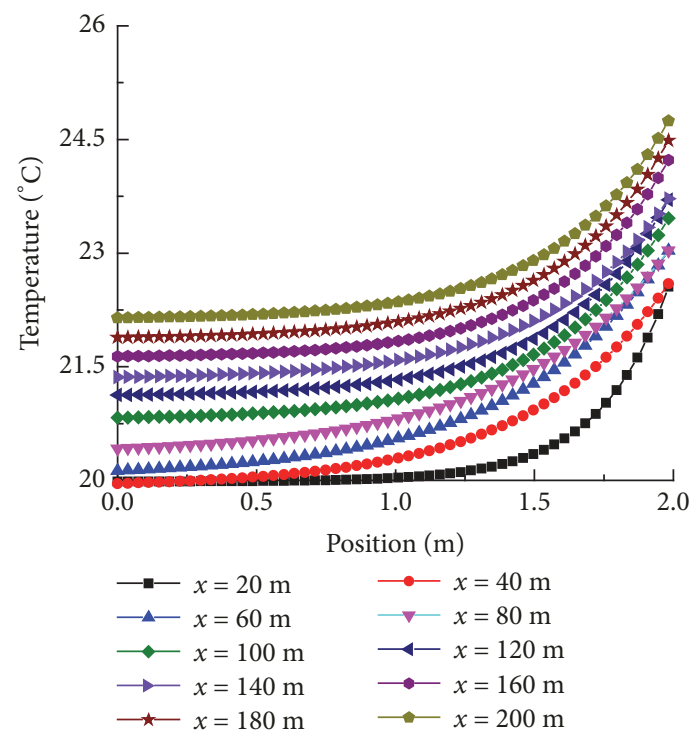

(d) Ventilation for 24 months

FIGURE 5: The change of airflow temperature with the ventilation time at different sections.

nonlinear characteristics while the ventilation time is less than six months. In addition, the difference of $K_{\tau}$ at different sections gradually decreases with the extension of ventilation time, and the value of $K_{\tau}$ eventually stabilizes. For example, the difference of $K_{\tau}$ at 2 months is 1.96 , but was just 0.06 at 24 months. Above results indicate that convection heat transfer is more intense and heat flow density is larger at the initial stage of ventilation, and the change of $K_{\tau}$ also tends to be stable with the heat transfer approaching equilibrium. Therefore, the unsteady heat transfer is the key factor leading to the nonlinear characteristics of $K_{\tau}$.

\section{Conclusion}

The physical model of heat insulation supporting roadway is constructed, and the heat transfer control equations are established based on basic assumptions and considering heat and moisture exchange. The model is solved by using FLUENT software, and the temperature field distribution of airflow and surrounding rock is obtained. By analyzing the numerical results, the main conclusions are as follows.

There is no obvious difference in the distribution of temperature field between thermal insulation supporting roadway and common supporting roadway. The main function of heat insulation supporting structure is to weaken the convection heat transfer between surrounding rock and airflow, which is helpful to the auxiliary cooling of high temperature mine.

The variation trend of airflow temperature field is similar whether in radial or in axial direction. Overall, the rate of heat exchange gradually decreases with the heat exchange becoming more and more sufficient. In boundary layer, due to 


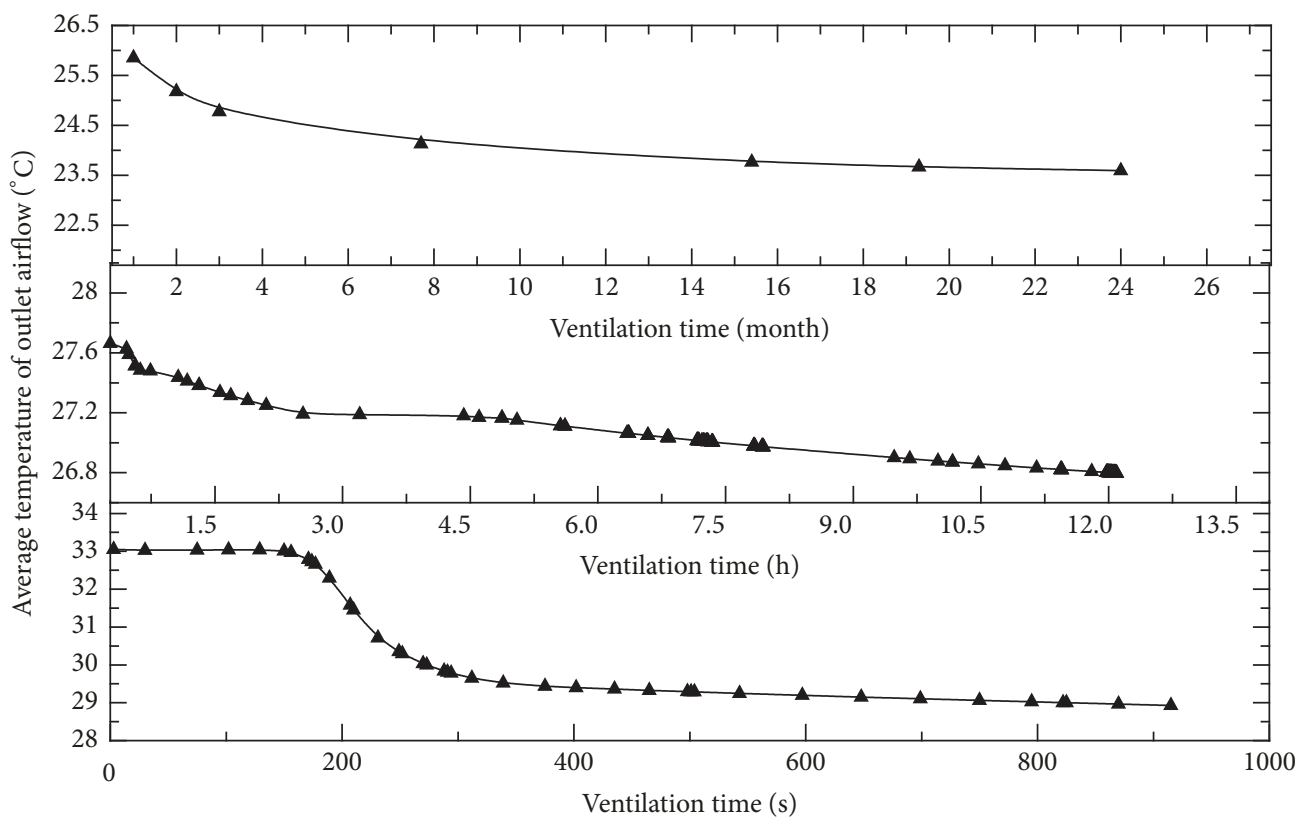

FIGURE 6: Change of average temperature of airflow at outlet with ventilation time.

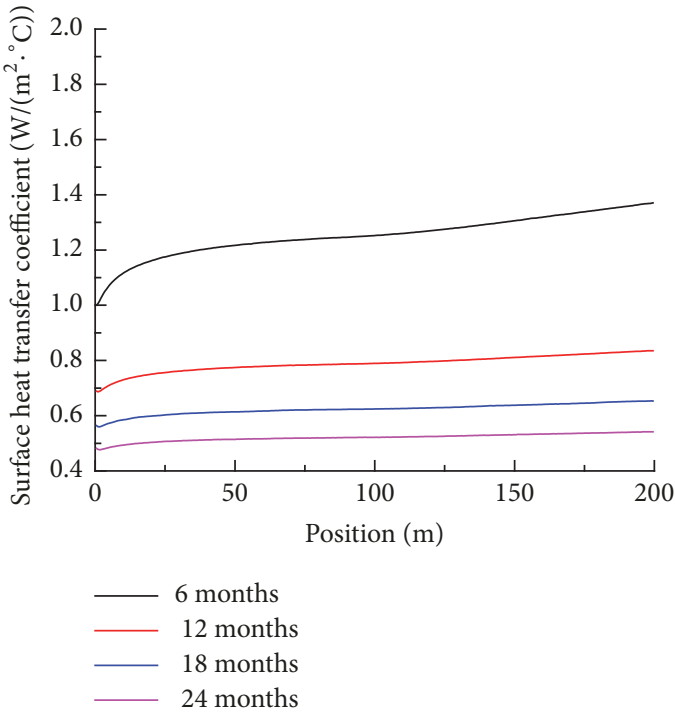

FIgURE 7: The changes of $K_{\tau}$ with the axial locations.

intense collisions of airflow masses, the airflow temperature quickly transits from the wall temperature to that of the main airflow area.

At the beginning of ventilation, the airflow temperature at outlet changes frequently and becomes stable after 12 hours under the action of heat-moisture exchange. Hereafter, the effect of heat insulation support on heat dissipation of surrounding rock gradually appeared, and the airflow temperature showed a trend of steady decline.

The surface heat transfer coefficient is well consistent with the unstable heat-humidity transfer, which is reflected by the obvious change in the beginning of ventilation or at airflow

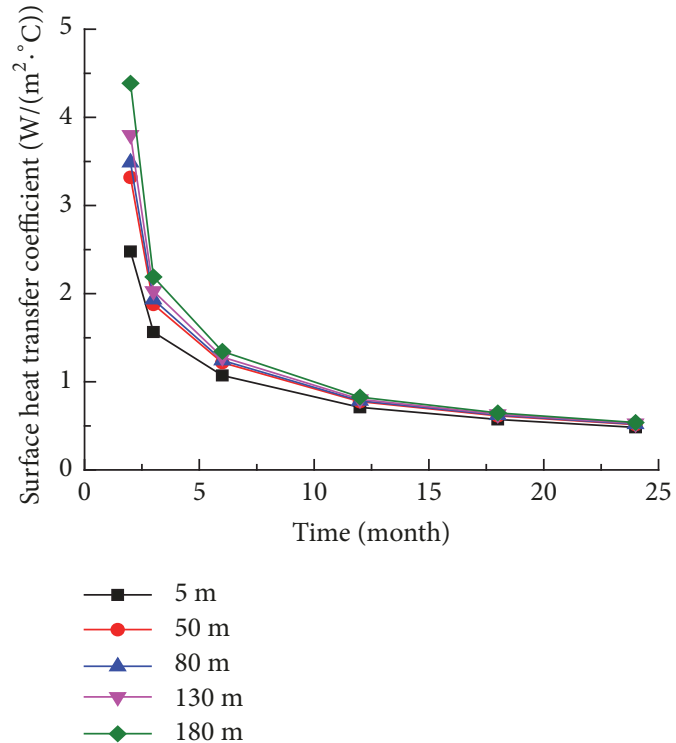

FIGURE 8: The changes of $K_{\tau}$ with the ventilation time. inlet. This is also consistent with the temperature change of the air flow at the outlet.

\section{Data Availability}

The data used to support the findings of this study are available from the corresponding author upon request.

\section{Conflicts of Interest}

The authors declare no conflicts of interest regarding the publication of this paper. 


\section{Acknowledgments}

The present study was financially supported by the National Natural Science Foundation of China (51574141; 51604142). Special thanks are given to Professor Zhang Shuguang for providing technical support.

\section{References}

[1] Y. Zhang, Z.-J. Wan, B. Gu, C.-B. Zhou, and J.-Y. Cheng, "Unsteady temperature field of surrounding rock mass in high geothermal roadway during mechanical ventilation," Journal of Central South University, vol. 24, no. 2, pp. 374-381, 2017.

[2] B.-X. Xie, Y.-J. Chen, and X.-Z. Shi, "IRMR method for evaluation of surrounding rock quality in deep rock mass engineering," Journal of Central South University (Science and Technology), vol. 38, no. 5, pp. 987-992, 2007.

[3] Z.-J. Wan, Y. Zhang, J.-Y. Cheng, C.-B. Zhou, B. Gu, and P. Zhou, "Mine geothermal and heat hazard prevention and control in China," Disaster Advances, vol. 6, pp. 86-93, 2013.

[4] J. Knechtel, "Thermal hazard prevention in longwalls run under extreme geothermal conditions," Archives of Mining Sciences, vol. 56, no. 2, pp. 265-280, 2011.

[5] H. Yan, J.-X. Zhang, L.-Y. Li, and R.-M. Feng, "Stability assessment of rock surrounding an I-beam supported retreating roadway," Journal of Central South University, vol. 22, no. 9, pp. 3598-3607, 2015.

[6] T. R. Roy and B. Singh, "Computer simulation of transient climatic conditions in underground airways," Mining Science and Technology, vol. 13, no. 3, pp. 395-402, 1991.

[7] P. D. Sun and C. Q. Zhu, "Study on the geothermal fields of country rock on deep tunnels," Journal of China University of Mining and Technology, vol. 19, pp. 27-34, 1989.

[8] Y. P. Qin, H. Wang, K. Y. Guo, P. F. Xue, J. W. Wang, and J. S. Wu, "Simulation of finite volume method and experimental analysis for temperature field of roadway surrounding rock," Journal of the China Coal Society, vol. 42, no. 12, pp. 3166-3175, 2017.

[9] Z. Yuan, Z. J. Wang, G. Bin, H. W. Zhang, and P. Zhou, "Finite difference analysis of transient heat transfer in surrounding rock mass of high geothermal roadway," Mathematical Problems in Engineering, vol. 2016, Article ID 8951524, 7 pages, 2016.

[10] E. Dong and L. Guan, "Numerical simulation on local ventilation in the mine tunnel," Advanced Materials Research, vol. 5, pp. 446-449, 2012.

[11] J. Q. Tan, Y. W. Ju, Q. L. Hou, W. Y. Zhang, and Y. J. Tan, "Distribution characteristics and influence factors of present geotemperature Su-Lin Huaibei coalfield," Chinese Journal of Geophysics, vol. 52, pp. 732-739, 2009.

[12] S.-G. Zhang, "Numerical simulation analysis of temperature field in surrounding rock of deeply buried roadways," Engineering Science and Technology, vol. 6, no. 14, pp. 2194-2196, 2006.

[13] M. A. Abdous, H. B. Avval, P. Ahmadi, N. Moallemi, and I. Dincer, "Analysis of transient heat conduction in a hollow sphere using Duhamel theorem," International Journal of Thermophysics, vol. 33, no. 1, pp. 143-159, 2012.

[14] J. Cygankiewicz and J. Knechtel, "The effect of temperature of rocks on microclimatic conditions in long gate roads and galleries in coal mines," Archives of Mining Sciences, vol. 59, no. 1, pp. 189-216, 2014.

[15] Y. A. Khokholov and A. S. Kurilko, "Heat exchange of rock and filling masses in kimberlite mining," Journal of Mining Science, vol. 40, no. 1, pp. 31-36, 2004.
[16] J. J. Gao, W. Xu, and X. B. Zhang, "Treatment of water evaporative during calculation of temperature and humidity of airflow caused by heat release from surrounding rock," Journal of the China Coal Society, vol. 35, pp. 951-955, 2010.

[17] Y. Zhang, Z. J. Wan, B. Gu, and C. B. Zhou, "An experimental investigation of transient heat transfer in surrounding rock mass of high geothermal roadway," Thermal Science, vol. 20, pp. 53-53, 2016.

[18] W. Yao, J. Y. Pang, J. K. Huang, and W. Yan, "Experim entalresearch on a new therm alinsulating shotcrete performance in deep roadway," Concrete, pp. 134-138, 2017.

[19] Y. F. Zhang, J. F. Ni, and W. Z. Dai, "Study on influencing factors of temperature and humidity of airflow in roadway based on theory of heat and moisture exchange," Chinese Journal of Safety Science and Technology, vol. 15, pp. 118-123, 2019. 


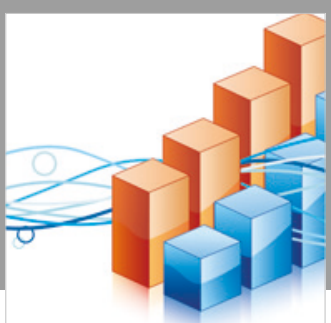

Advances in

Operations Research

\section{-n-m}
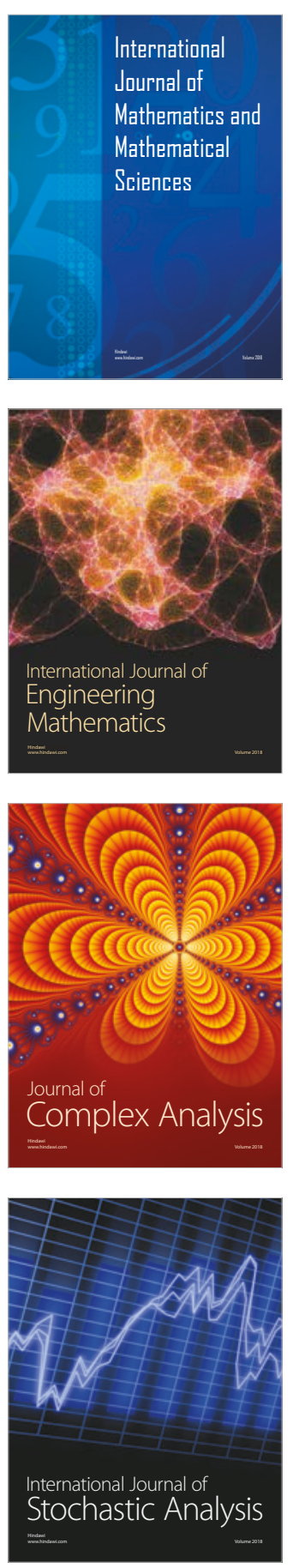
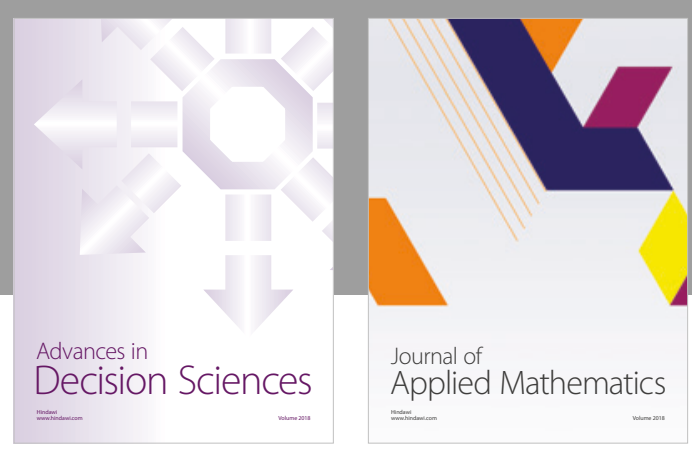

Journal of

Applied Mathematics
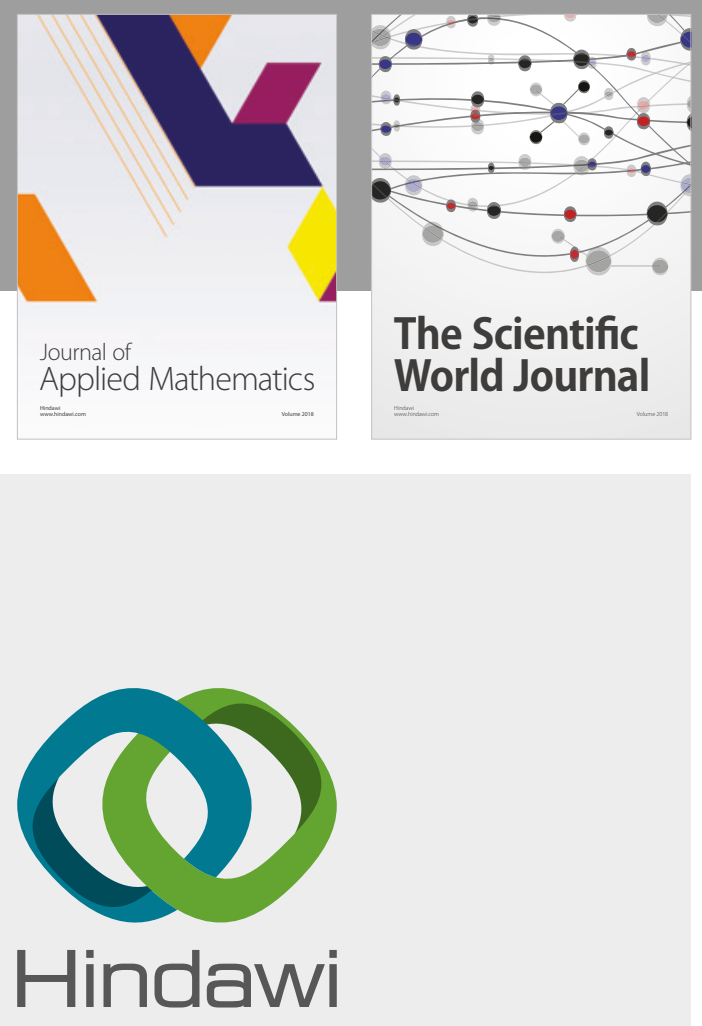

Submit your manuscripts at

www.hindawi.com

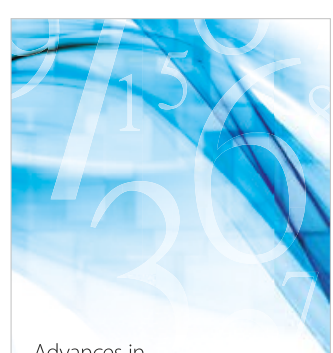

Advances in
Numerical Analysis
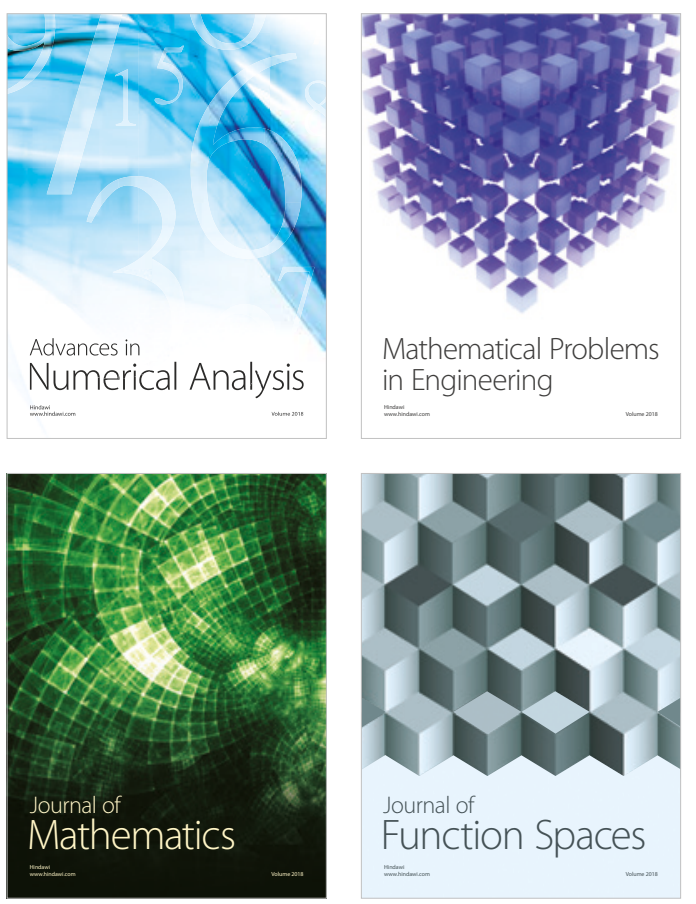

Mathematical Problems in Engineering

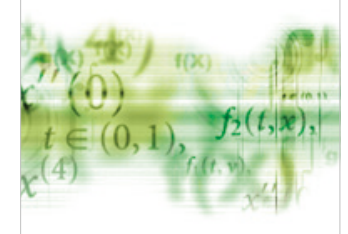

International Journal of

Differential Equations

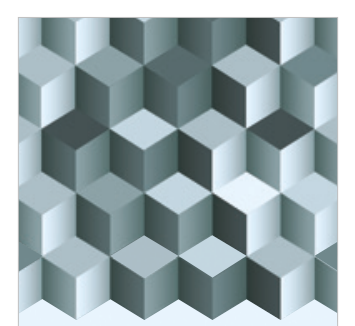

Journal of

Function Spaces

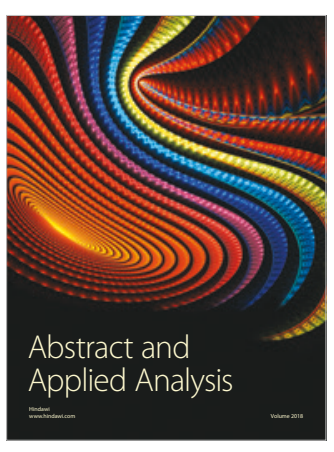

The Scientific

World Journal

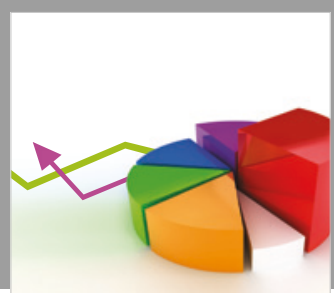

Journal of

Probability and Statistics
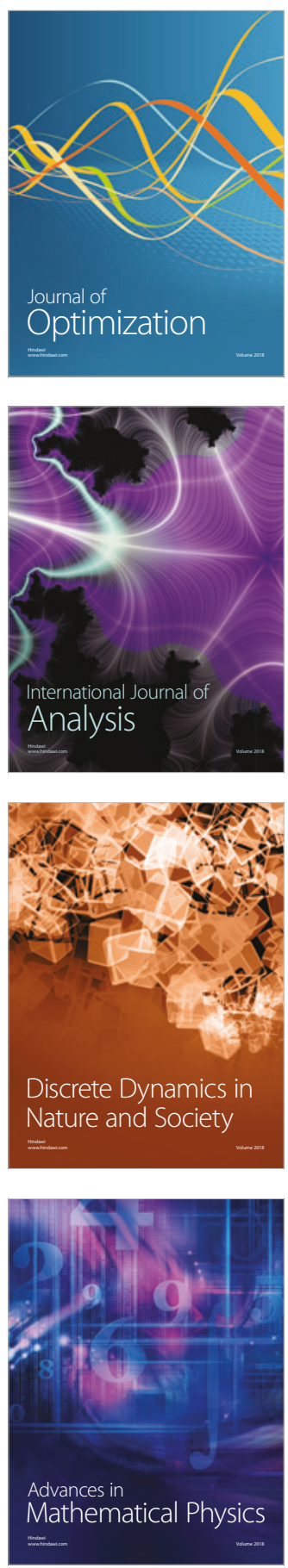